\title{
Plastics and Some Recent Applications
}

\author{
By H. V. Potter
}

C ONSIDERABLE progress has been made in the practical application of plastics in every sphere since the author's review which appeared in Nature of March 9, 1935. Moulded radio cabinets were then just being introduced, and these were regarded as a great step forward since they represented by far the largest mouldings which had at that time ever been made. The advent of these large mouldings meant far more than capturing the radio cabinet market. Their introduction entailed the installation of larger and more powerful presses in moulding works, and once presses of this type had been purchased efforts were made to find uses for them, and larger mouldings followed as a natural corollary.

Probably the largest mouldings ever made are the standard-sized coffins or caskets which are now in experimental production. These require a press of approximately 4,000 tons capacity, and each casket uses nearly $95 \mathrm{lb}$. of moulding material in its production. Although the consistent increase in size of mouldings is an indication of progress, improvement is primarily noticeable in the materials from which the mouldings are produced.

It is proposed to confine attention in this review to those synthetic resinous plastics which have already attained an important position in industry. A brief perusal of the patent literature will disclose that hundreds of new plastics have been proposed in recent years, most of which will progress no farther than publication of the patent. From the industrial point of view, the two most important synthetic resins are the phenol-formaldehyde and urea formaldehyde types, both of which are thermo-setting. From each of these, moulded materials and laminated materials are produced, while they are also employed in paints and varnishes in place of natural resin.

A brief outline of the manufacture of phenol products-better known, perhaps, as 'Bakelite' materials-may assist those who are not familiar with the process. Basically, the production of urea materials, once the resinoid has been made, is similar to the methods adopted for manufacturing phenolic moulding powders and laminated sheet.

By mixing phenol and formaldehyde in a heated reaction vessel together with a suitable catalyst, a reaction occurs which results in the formation of a heary viscous mass at the bottom of the vessel with a layer of water above it. When the upper layer has been removed by evaporation, the remaining material is tapped off and allowed to cool. It is then a brittle, amber-like solid which can be softened by heating. Continued application of heat, however, causes this 'resinoid', as it is termed, to become permanently hard and insoluble. Moulding powders are made by pulverizing the initial resinoid and mixing with it various fillers, pigments, mould lubricants, plasticizers, etc. The ultimate result of this processing is a powder from which the moulder produces the finished moulding by charging pre-determined quantities into heated steel moulds which are then closed under pressure. The properties of the mouldings can be varied by changes in the resinoid formula and by differing types and proportions of filler. In this manner the moulding material manufacturer can ensure, within limits, that any desired characteristic shall be present in the finished moulding. Good dielectric properties, low power losses at very high frequencies, resistance to heat, water or chemicals are typical examples of the many grades of material which have been developed to meet some specific requirement.

In a similar manner, the properties of laminated. materials can be varied, but within much narrower limits, since the manufacturer is restricted in his choice of fillers. These laminated materials are built up by impregnating sheets of paper or fabric with resinoid and forming many such sheets into a solid board under heat and pressure. The material is produced ranging from a few thousandths of an inch in thickness for some types of electrical insulation up to a maximum thickness of 4 inches for gears. Yet another grade of laminated material is employed for decorative purposes. Veneers and wall panels are now in regular production and are used for the surfacing of walls and furniture in the home, hospitals, offices, hotels, restaurants and all types of public buildings. A surprisingly wide range of beautiful colours-pastel shades, black, white, mottles and wood grain patterns-is available, and the materials also embody unusual and valuable properties. They are unaffected by steam or moisture and are resistant to heat, fruit-juices and alcohol. Their surface does not corrode and, being non-hygroscopic, is hygienic and easily kept clean.

The range of present-day uses of plastics is so wide and so important that it is impossible fully to describe their applications in the space of this 
article. Since engineering uses are now very much to the fore, some of the more interesting developments in this sphere will be outlined. The aircraft industry finds many uses for plasties. Phenol plastics are mechanically strong and their weight is only half that of aluminium. This fact, combined with the ease with which moulded parts can be produced, provides a tempting prospect for the aircraft engineer, and it is reasonably certain that moulded fuselages, wings, etc., will be pressed out of plastic material in the not too distant future. The size of mouldings has hitherto been a drawback but, as mentioned earlier, moulded coffins have been made and moulded sheets of laminated paper and wood h ave been manufactured up to 20 -ft. in length. For large structures, such as an aeroplane fuselage, wood reinforced with synthetic resins has an i m portant future. The latest developments here follow closely along the lines of laminated

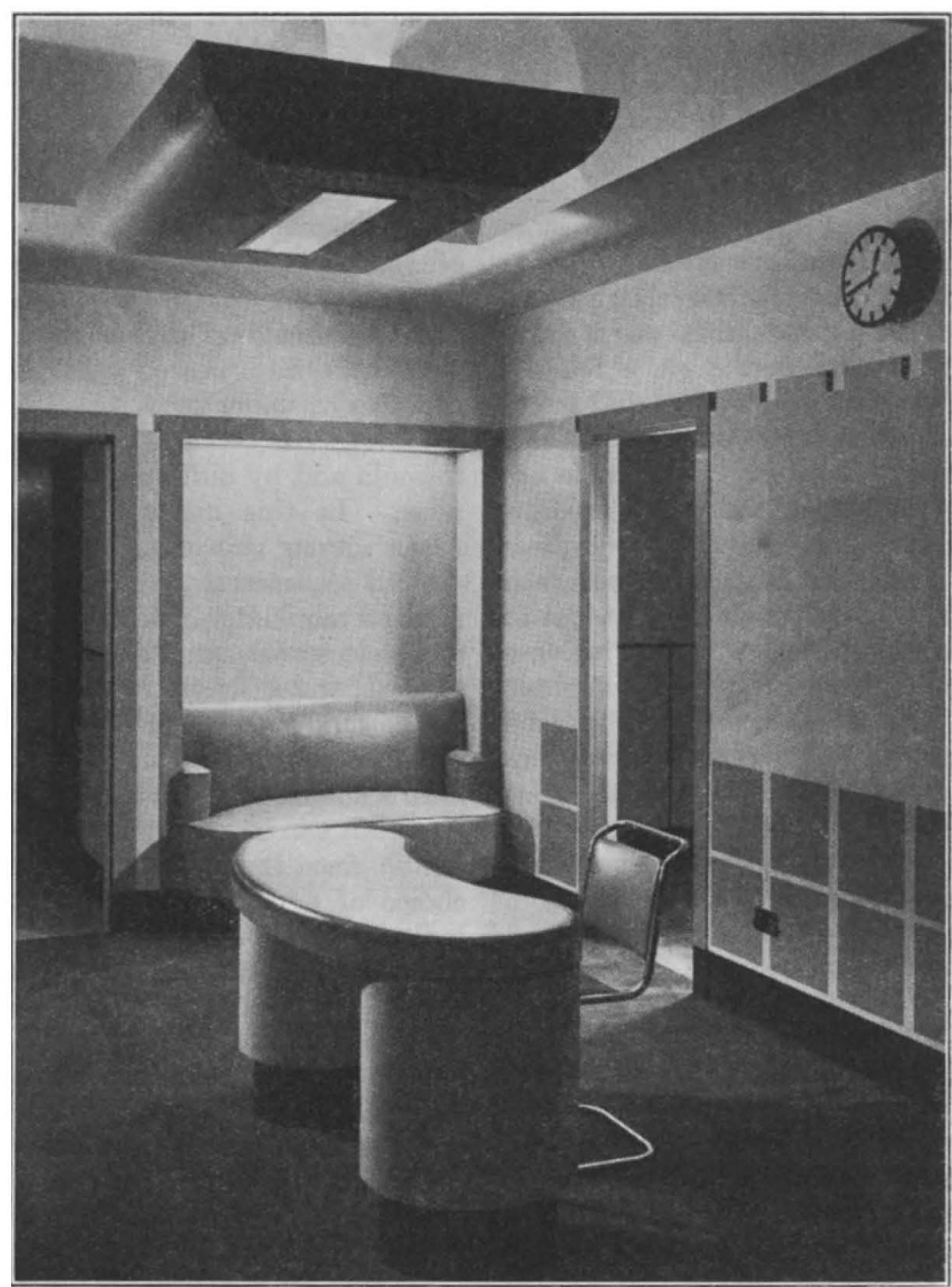

Application of plastics In Decorations. The walls as well as THE DESK ARE SURFACED WITH 'BAKELITE' VENEERS. length of the blade except where necessitated by the gradually decreasing cross-section. A core is accurately located in the centre of the blade and around this the reinforced material is moulded and compressed. A high-frequency furnace is employed to melt the core metal without damaging the blade.

An organic glass, obtained from methyl methacrylate, which is one of the thermoplastic resins, is replacing ordinary glass for wind shields, observation turrets, etc., in aircraft. It is light in weight, has a good re. fractive index and will not splinter on im. pact.

Many small components in aircraft construction are produced from plastics, in. cluding barrel supports for variable pitch a irs crews, shims, chafing rings, etc. There is no doubt, too, that if a synthetic resin having much greater $\mathrm{ph} \mathrm{y} \mathrm{s} \mathrm{i} \mathrm{c} \mathrm{a} \mathrm{l}$ strength and elastic pro. perty could be developed, the field of application for plastics material practice, that is, veneers of wood are treated with 'Bakelite' resins, built up into boards of required size and consolidated under heat and pressure.

Another recent development is the moulded airscrew blade shown in the photograph opposite. This is probably the largest moulding yet made in which continuous lengths of fabric have been used. The threads at the root end forming the flange are unbroken throughout the whole would be far wider. Research is continually proceeding in an endeavour to attain this object, and it must eventually be achieved. The limit has almost been reached for increasing the mechanical strength of plastic materials by differing types of filler.

Synthetic resins have made possible a great improvement in plywood, which is of particular importance for aircraft work. Phenolic resins incorporated on paper are employed as the 
adhesive for the various plies of a plywood board. The paper is of tissue thickness and is merely a vehicle for providing a resin film in convenient form. The plies with the impregnated paper interleaved between them are formed into a solid board in a hot press, the heat causing the resin film to flow, penetrating the wood and finally polymerizing. In contrast to ordinary plywood glues, the strength of the synthetic resin bond is actually increased by immersion in water. This remarkable water resistance, and the fact that the adhesive is impervious to insects and fungus, greatly enhances the prospects of plywood for aero construction.

Two important applications of phenolic laminated materials in engineering are for the production of gears and bearings. The material is easily machined by standard workshop methods, and gears transmitting up to 300 h.p. are now made from it. One or more of these plastics gears in a gear train results in a considerable reduction of noise and they have other advantages due to their chemical resistance. Wherever bearings of phosphor bronze, white metal or lignum vitæ have been used previously, consideration may advantageously be given to the synthetic resin bearing. Far longer life is frequently obtained and the sole lubricant required is water. The material is not, of

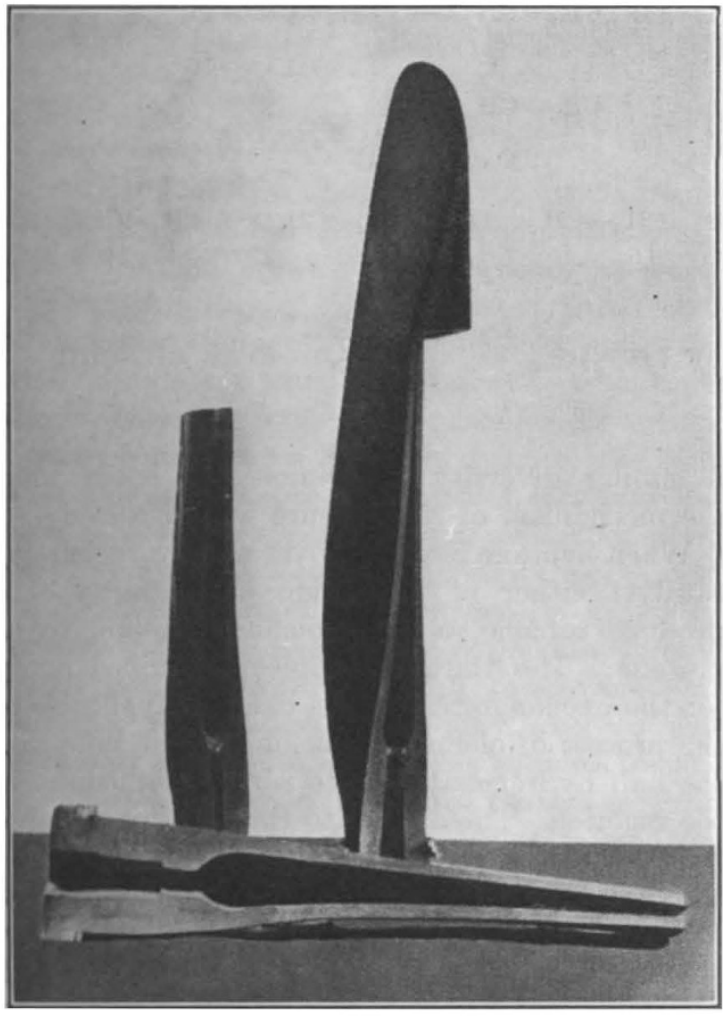

A HOLLOW MOULded BLADE FOR A VARIABLE PITCH AIR-SCREW, 6 FT. FROM CENTRE TO TIP.

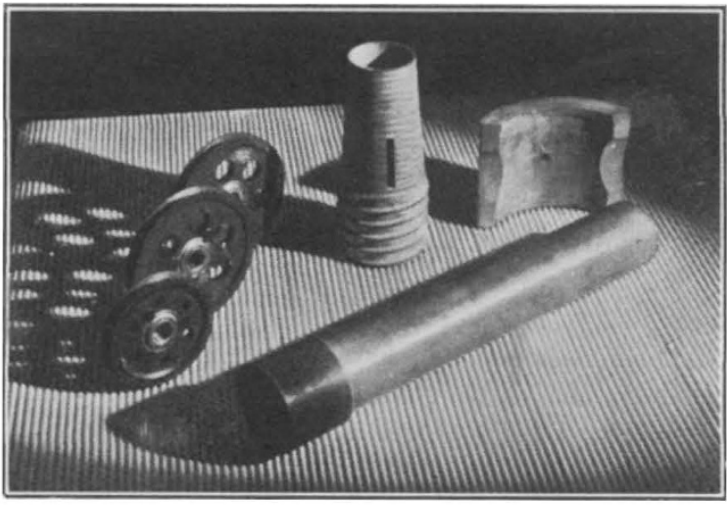

CONTROL PULLEYS, BARREL SUPPORT AND UNDERCARRIAGE PISTON USED IN MODERN AIRCRAFT, MACHINED FROM PHENOLIC LAMINATED MATERIAL.

course, suitable for use for components in highspeed engines.

The applications of plasties to-day are extraordinarily diverse. Thousands of mouldings are made daily and are used in almost every industry. More than seven million insulating components punched from laminated material may be used in a single telephone exchange. Matrices for printing stereos are made from a phenolic material, dentures are made from the pure resinoid, and, in the form of lacquers, varnishes and cements, synthetic resins are assisting industry in many ways. Yet despite the progress which has been made in the past four years, it is not too optimistic to forecast that progress in the next four years will be even more rapid.

The resins more recently developed, such as vinyl and polystyrene, are slowly making headway for uses to which they are better suited than the earlier resins. These materials can be moulded by the injection process, that is, forcing the resinoid (which has previously been plasticized by heat) through an orifice into a closed mould, in place of the older method of using the resinoid in powdered form. The vinyl and polystyrene resins have valuable properties some of which are not possessed by the other resinoids. They have a water-white transparency, good electrical properties and excellent water resistance. They are, however, thermoplastic and can, therefore, be softened repeatedly by heat while, as already noted, the phenolic and urea resinoids are permanently hardened by heating.

There has been a good deal of development in connexion with the equipment for injection moulding, and machines are now available which work almost automatically except for switching on the electric current and keeping the feeding hopper filled with the resinoid. Further important advances in the mechanization of press operations will undoubtedly be seen in the future. 